\title{
Papillary Thyroid Cancer of Thyroid Implants in Soft Tissue Neck after 15 years of Thyroid Surgery for Benign Pathology
} \author{
Agarwal $^{2}$ \\ ${ }^{1}$ Department of Genetics, Sanjay Gandhi Postgraduate Institute of Medical Sciences, India \\ ${ }^{2}$ Department of Endocrine Surgery, Sanjay Gandhi Post Graduate Institute of Medical Sciences, India \\ ${ }^{3}$ Department of Pathology, Sanjay Gandhi Postgraduate Institute of Medical Sciences, India \\ ${ }^{4}$ Department of Anatomy, Hind Institute of Medical Sciences, India
}

Ashok Kumar' ${ }^{1}$ Gyan Chand ${ }^{2 *}$, Amit Agarwal ${ }^{2}$, Narendra Krishnani ${ }^{3}$, R.N.Rao ${ }^{3}$, Adarsh Ranjan ${ }^{4}$ and Sudhi

Submission: June 26, 2017; Published: June 30, 2017

*Corresponding author: Gyan Chand, Endocrine Surgery department, Sanjay Gandhi Post Graduate Institute of Medical Sciences, Lucknow, India, Tel: 91-9451546353; Fax: 91-522-2668777; Email: drchandpgi@gmail.com

\begin{abstract}
Background: In patients with long standing multinodular goiter, sometime it is difficult to differentiate lateral thyroid nodules from cervical lymph nodes. These nodules may be detached thyroid nodules, embryonic thyroid rests or thyroid implants after surgery.

Case presentation: We describe here one such case who presented with similar difficult situation. She had thyroid surgery for benign goiter many years back and then developed recurrent multinodular goiter and lateral neck swellings. On clinical examination and imaging lateral neck nodules could not be differentiated between lymph node masses and lateral thyroid nodules. Total thyroidectomy with bilateral modified radical neck dissection was done. On histopathology of thyroid it shows Papillary thyroid cancer and all lateral neck masses showed no lymphoid architecture while having same morphology as that of thyroid. Patient received adjuvant radioactive iodine ablation and in eight months follow up till now is disease free.
\end{abstract}

Conclusion: Surgery or trauma can lead to implantation of thyroid cells in the soft tissue of neck and may present as multiple thyroid nodules. Keywords: Thyroid implants; Thyroid surgery; Detached thyroid nodules

\section{Back Ground}

Patients presenting with long standing huge multinodular goiters may present with multiple nodules in the lateral neck, sometime it is very difficult to differentiate thyroid nodules from cervical lymphadenopathy on clinical, radiological and histological evaluation. If patients present with recurrence after surgery for benign thyroid nodules, very rarely they may be associated with thyroid implants in the soft tissue of neck or detached thyroid nodules or cervical lymphadenopathy with complete replacement by thyroid tumor cells [1].

\section{Case Presentation}

A 50 year woman operated for benign thyroid nodule fifteen years back for euthyroid benign thyroid nodules at government medical college, presented with gradually progressing swelling in front of neck for last three years with rapid increase for

three months. She had symptoms of tracheal and esophageal compression with dyspnea even at rest and haemoptysis for one week. There was history of recent loss of appetite and voice change. She had stridor, tachycardia and tachypnea at the time of examination. A huge multi nodular goiter measuring $20 \times 16 \mathrm{~cm}$, was present with firm to hard consistency, restricted mobility, lower border was not reachable and bilateral carotids were displaced posterolaterally. There were multiple nodules present in the neck more on lateral sides but it was difficult to differentiate them from cervical lymphadenopathy due to absence of planes between the thyroid lobes and lateral neck mass. She was admitted in emergency and managed for respiratory distress in form of bed rest, oxygen by mask, steroids, intravenous antibiotics and fluids. She improved symptomatically but on $2^{\text {nd }}$ day she deteriorated and required ventilator support. 
Her fine needle aspiration cytology from thyroid was reported as papillary thyroid cancer with poorly differentiated area/Insular carcinoma and on contrast enhanced computerized tomogram it was reported as multinodular goiter with bilateral central and large lateral compartment lymphadenopathy. Her general condition improved and then she underwent Total thyroidectomy with bilateral Modified Radical Neck Dissection (MRND) in the same admission. Intra-operatively bilateral lobes of thyroid were densely adhered to tracheal surface, strap muscles and adjacent lymph nodes in central compartment. Strap muscles infiltrated were removed and tumor was shaved from tracheal surface at right side. Bilateral level II-V cervical lymph nodes were enlarged (Figure 1). Bilateral superior laryngeal nerves could not be visualized, left side recurrent laryngeal nerve was identified and preserved but right side recurrent laryngeal nerve was sacrificed as being involved by tumor mass. Bilateral inferior parathyroid glands were identified and preserved but superior parathyroid glands could not be visualized. Postoperatively patient had hypocalcaemia which was managed with oral and intravenous calcium. She had tracheomalacia for which tracheostomy was done and discharged on tracheostomy. On gross examination of operated three labeled specimens were sent for histopathological examination.

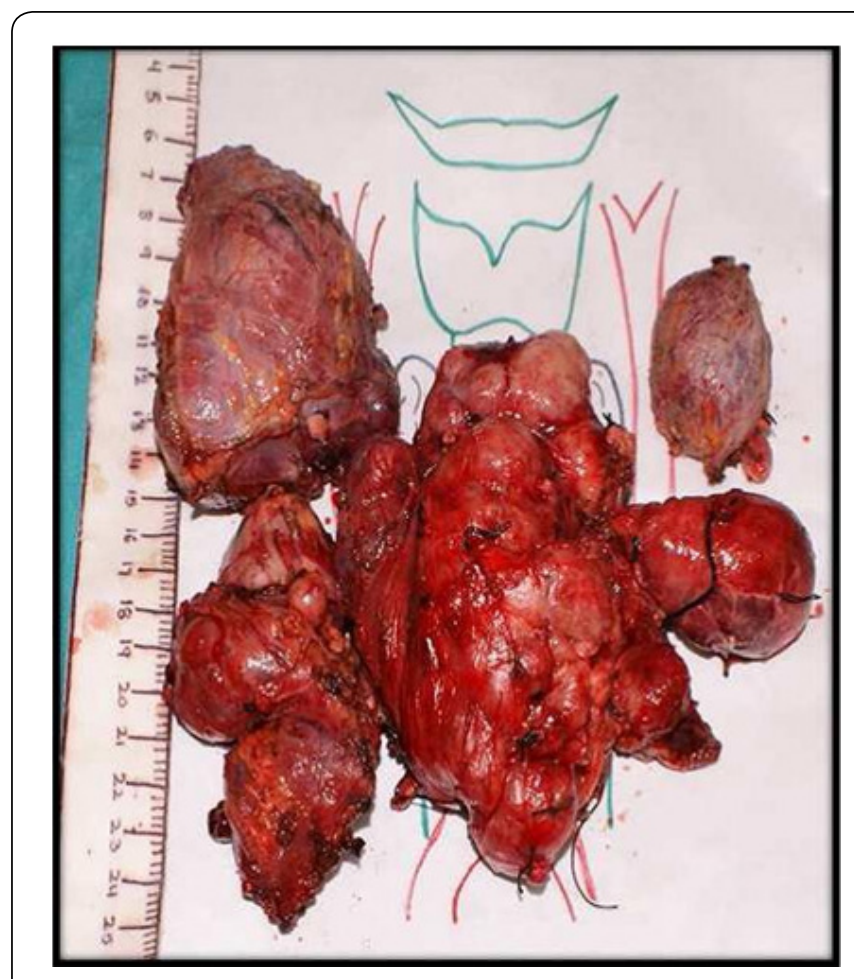

Figure 1: Gross postoperative.

\section{Total thyroidectomy specimen}

Right lobe measuring $12 \times 7 \times 6 \mathrm{~cm}$, isthmus measuring $1.5 \times 0.5 \mathrm{~cm}$ and left lobe measuring $4 \times 3 \times 2 \mathrm{~cm}$. The outer surface of right lobe was nodular and the cut surface showed multiple well defined to ill-defined nodules with areas of hemorrhage and sclerosis. The cut surface of left lobe also showed a nodule replacing whole lobe and measured $4 \mathrm{~cm}$ in diameter. No normal thyroid parenchyma identified grossly.

\section{Right MRND}

Two tissue pieces, larger measuring $9 \times 6 \times 5 \mathrm{~cm}$ and smaller measuring $7 \times 4 \times 3 \mathrm{~cm}$. Outer surface was nodular and grey white similar to thyroid nodules.

\section{Left MRND}

Single grey brown tissue piece measuring $4 \times 3 \times 2.5 \mathrm{~cm}$. Cut surface showed few well defined nodules with grey white surface.

\section{Histology}

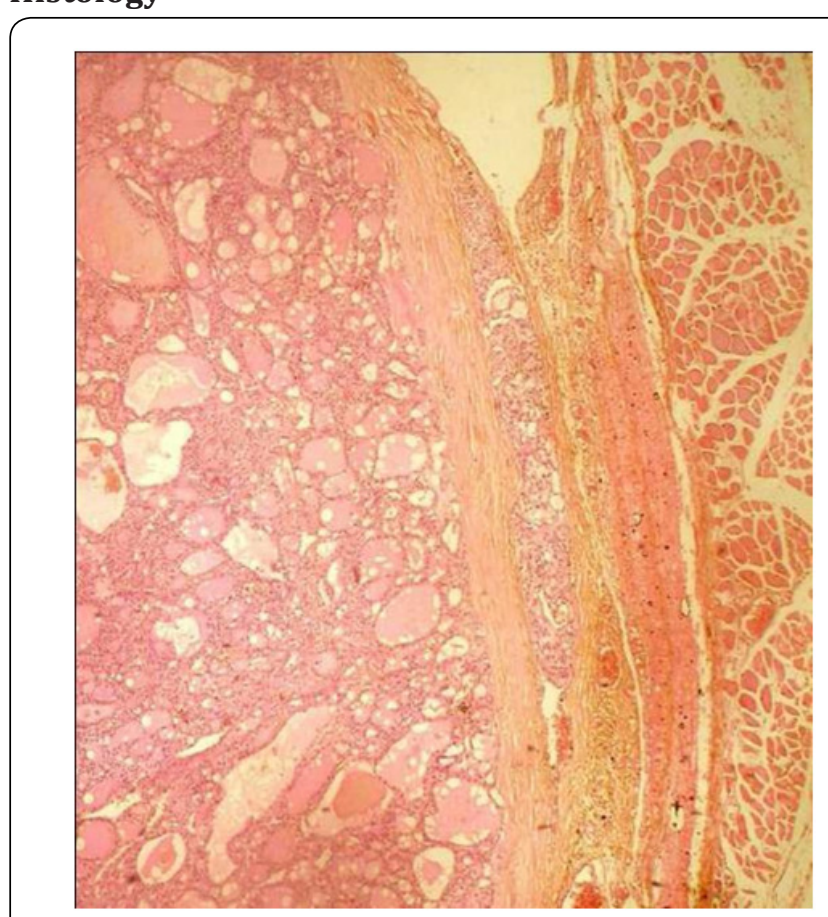

Figure 2: Histopathological features.

The sections reveal a malignant cellular tumor surrounded by variably thickened fibrous capsule with extension of fibrous septa into tumor parenchyma leading to formation of well-defined to ill-defined nodules. The tumor is arranged predominantly in micro follicular configuration with small round follicles composed of cubocolumnar follicular epithelial cells having isomorphic to mildly anisomorphic round nuclei, granular chromatin and variable eosinophilic cytoplasm. Colloid was also identified in follicular lumen (Figure 2). Areas of poor differentiation (20\%) with solid, insular and trabecular pattern of growth having small darker nuclei with convolutions of the nuclear membrane (convoluted or raisin like), with few nuclear grooving and occasional pseudo inclusions. Areas of sclerosis, hemorrhage and cystic degeneration were identified. Few mitotic figures were identified in solid areas. Few foci of vascular and capsular invasion are noted. The section from left lobe nodules show encapsulated tumor with similar morphology. The 
sections from separately sent both right and left MRND specimen show similar tumor morphology surrounded by irregular fibrous capsule. Any lymphoid cell collection at the periphery was not seen in any of the nodule of MRND specimen.

\section{Discussion and Conclusion}

There has been a lot of debate on significance of thyroid tissue found laterally in neck. The differential diagnosis of such masses includes several conditions like lymph node deposits of thyroid carcinoma with partial or complete replacement by tumor tissue, "benign metastatic thyroidosis," detached thyroid nodules, and true ectopic thyroid tissue and even work has been done on colonel analysis which may help in detection of the etiological factors [2]. It is important to recognize that surgery or trauma that leads to implantation of cells derived from thyroid tumors in soft tissues of the neck can lead to multiple palpable nodules many years later [3]. When careful study of the thyroid from these cases revealed the presence of minute primary papillary carcinoma, the diagnosis of lateral aberrant thyroid fell into disuse, and most of these deposits were regarded as metastatic lesions.

In our case, as we could not get the details of histopathology of first surgery done elsewhere it seems to benign but difficult to comment whether it was implantation of thyroid tissue during manipulation in surgery or it was recurrence with dedifferentiation. The rapid growth in the thyroid swelling may be due to dedifferentiation as confirmed by the final histopathology report describing poorly differentiated areas in the specimen. Our pathologists took finer sections to look for any lymphoid architecture but even in spite of repeated sections could not find any lymphoid tissue in any of the lateral neck masses. It could have been a possibility that entire lymph nodes were completely effaced by the thyroid tumor metastases but at least in any of the neck masses we should have few areas of lymphoid architecture peripherally or anywhere but we failed to find any in our specimen on repeated evaluations.

The various etiologies described for detached thyroid nodules include degenerative nature of long standing multinodular goiter; part of it may get ischemic in due course of time and get detached [4]. Gravitational force and negative thoracic pressure leads to descent of these detached thyroid nodules inferiorly in mediastinum. Other reasons include embryonic rests in par tracheal surface, esophagus. Some detached thyroid nodules may still be connected by flimsy tissue or vascular pedicle to main thyroid tumor mass.
There are few case series of detached thyroid nodules due to its rarity [5]. In our case there was no lymphoid tissue found in any of the lateral masses. Post surgical implants are often multiple unlike detached thyroid nodules which are usually large single and in mediastinum. Hence, we must keep these differentials in our diagnosis while managing such patients and details of surgery and histopathology are very vital in deciding about the final cause of lateral neck masses.

\section{Acknowledgement}

We would like to thank the patient described herein for agreeing to participate in this Case report and for her contribution to medical literature on this subject.

\section{Availability of Data and Materials}

Data sharing not applicable to this article as no datasets were generated or analyzed during the current study.

\section{Authors' Contribution}

Ashok Kumar, Adarsh Ranjan, Sudhi Agarwal, Gyan Chand were responsible for literature review, synthesis of evidence, and construction and editing of the manuscript. Gyan Chand and Amit Agarwal provided expert advice on management of thyroid cancer. Narendra Krishnani and R N Rao performed histological examination of the subjects. All authors read and approved the final manuscript.

\section{Consent for Publication}

The patient described in this report has given her express, informed consent for publication of this case and has completed our institutional consent form to that effect.

\section{References}

1. Kozol RA, Greelhoed GW, Flynn SD, Kinder B (1993) Management of ectopic thyroid nodules. Surgery 114(6): 1103-1107.

2. Kakudo K, Shan L, Nakamura Y, Inoue D, Koshiyama H, et al. (1998) Clonal analysis helps to differentiate aberrant thyroid tissue from thyroid carcinoma. Hum Pathol 29(2): 187-190.

3. Panunzi C, Paliotta DS, Papini E, Rinaldi R, Nardi F, et al. (1994) Cutaneous seeding of a follicular thyroid cancer after fine-needle aspiration biopsy? Diagn Cytopathol 10(2): 156-158.

4. Harach HR, Cabrera JA, Williams ED (2004) Thyroid implants after surgery and blunt trauma. Ann Diagn Pathol 8(2): 61-68.

5. Diggory RT, Wu Av, Sykes D (1991) Detached thyroid nodule. J R Col Surg Edinb 36(3): 195-196. 
This work is licensed under Creative Commons Attribution 4.0 Licens

DOI: 10.19080/GJIDD.2017.01.555570
Your next submission with Juniper Publishers will reach you the below assets

- Quality Editorial service

- Swift Peer Review

- Reprints availability

- E-prints Service

- Manuscript Podcast for convenient understanding

- Global attainment for your research

- Manuscript accessibility in different formats ( Pdf, E-pub, Full Text, Audio)

- Unceasing customer service

Track the below URL for one-step submission https://juniperpublishers.com/online-submission.php 